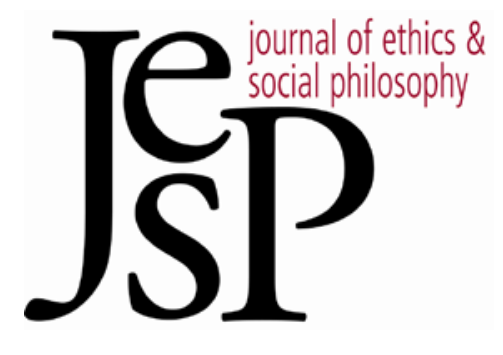

DISCUSSION NOTE

\title{
On the Democratic Value of Distrust
}

\author{
By ERICh Hatala Matthes
}

JOURNAL OF ETHICS \&SOCIAL PHILOSOPHY

Discussion NOTE | DECEMBER 2015 URL: WWW.JESP.ORG COPYRIGHT (C) ERICH HATALA MATTHES 2015 


\title{
On the Democratic Value of Distrust
}

\author{
Erich Hatala Matthes
}

\section{I} N HER RECENT PAPER “(WHITE) TYRANNY and the Democratic Value of Distrust," Meena Krishnamurthy argues that distrust has a political value that has often been overlooked by democratic theorists. ${ }^{1}$ Pursuant to making this argument, Krishnamurthy first offers an account of distrust based on the work of Martin Luther King Jr., and then argues for the democratic value of this conception of distrust. These two tasks are crucially related: Krishnamurthy's aim is not to engage in general conceptual analysis about distrust, but to show that the particular account of distrust that she presents is politically useful (392). For the purposes of this discussion, I would like to grant that distrust can be politically useful, which Krishnamurthy convincingly demonstrates through her examination of King and the Black Civil Rights Movement. Rather, in the spirit of Krishnamurthy's methodological approach, I will raise a few questions about whether the particular account of distrust that Krishnamurthy develops from King is in fact best positioned to capture distrust's political value. Moreover, I will argue that an alternative account of distrust might reveal distrust's noninstrumental political value, in contrast with the merely instrumental role it is granted by Krishnamurthy.

The centrality of belief is the most significant difference between the accounts of trust and distrust that Krishnamurthy develops from King and some of those elsewhere in the philosophical literature on (dis)trust. As Krishnamurthy puts it, on King's view, “distrust is the confident belief that another individual or group of individuals or an institution will not act justly or as justice requires"(391). Though distrust is the primary focus of the essay, Krishnamurthy also offers a preliminary take on King's account of trust: "To trust someone, on King's view, was to believe that they would not only act justly but also that they would act justly for the right reasons" (395).

In what follows, I will briefly state three general questions about the prominence given to belief in Krishnamurthy's discussion, and then draw them together by considering how the potential political value of Krishnamurthy's account compares with another recent account of distrust provided by Katherine Hawley. ${ }^{2}$

First, equating trust and distrust with beliefs renders these attitudes much less voluntary than they might otherwise be. By comparison, it is the sense that we must be able to decide to trust that leads philosophers such as Richard Holton to reject that trust requires a particular belief in the trusted and what they will do. ${ }^{3}$ So we might ask whether making distrust less volun-

\footnotetext{
${ }^{1}$ Krishnamurthy 2015. Cited in text hereafter.

${ }^{2}$ Hawley 2014

${ }^{3}$ Holton 2006; Jones 2004. See also Jones 1996.
} 
tary (assuming that acquiring beliefs is less voluntary than the adoption of other attitudes) has an effect on its political value. Might a more voluntary construal sit better with Krishnamurthy's characterization of distrust in terms of "checks and balances" on the abuse of political power? Indeed, if the political value of distrust consists, as Krishnamurthy argues, in its causal power to instigate actions that challenge tyranny (392), we might worry that a nonvoluntary construal of distrust will be relatively inert in comparison with a conception that would be responsive to a call to action.

Second, Krishnamurthy's account does not explicitly mention some of the common affective elements that we find in other theories of (dis)trust, such as Holton's inclusion of the participant stance, or Karen Jones' suggestion that distrust involves non-reliance plus resentment. Will we completely capture distrust's political value if these affective elements are absent from the account itself? Is mere belief sufficient to provide the kind of motivating force that makes distrust politically valuable in causing responsive action (401)?

Finally, we might wonder whether Krishnamurthy's account is sufficiently sensitive to the appropriateness of distrust, as Hawley discusses in her recent work on distrust. ${ }^{4}$ If distrust is just a matter of belief about others acting unjustly, then it may well be misplaced or ill formed (as beliefs are wont to be), contributing to the contingent nature of its political value (as Krishnamurthy acknowledges (401)).

We can bring these three general questions together by comparing Krishnamurthy's account of trust with Hawley's recent alternative. According to Hawley, "To distrust someone to do something is to believe that she has a commitment to doing it, and yet not rely upon her to meet that commitment." ${ }_{5}$ Moreover, this account includes the following condition on appropriateness: " $[\mathrm{T}$ is appropriate to trust or distrust someone to do something only if that person has an explicit or implicit commitment to doing it." 6 While there is still a role for belief in Hawley's account, distrust is not merely a belief. Rather, it hinges on a more voluntary element: to not rely on someone to meet the commitment that you believe she has.

Incorporating the idea of not relying on a commitment can help inject distrust with more of the motivating force that makes it politically valuable. On Krishnamurthy's account, it seems that one might have a confident belief that an institution is unjust (which is sufficient for distrust on her account), and yet rely on it anyway. This kind of distrust thus seems like it might lead to a kind of tragic political apathy instead of fomenting political resistance. ${ }^{7}$

\footnotetext{
${ }^{4}$ Hawley 2014.

${ }^{5}$ Hawley 2014: 10.

${ }^{6}$ Hawley 2014: 9.

7 Admittedly, it depends on how the belief that the system is unjust is cashed out. It may be that one cannot both believe not-X and rely on $\mathrm{X}$ (e.g., believe that you will not pick me up at the airport and rely on you to do so), in which case Krishnamurthy's account might have non-reliance built in implicitly. However, I take it that the belief in the injustice of a political
} 
By comparison, perhaps the decision not to rely on the unjust system, on top of the belief that it is unjust, would offer an account of distrust with greater political value given its more voluntary nature. Indeed, this alternative might also fit well with the causal story that Krishnamurthy offers about distrust in the Black Civil Rights Movement. Furthermore, this account gives us the resources to explain why distrust is appropriate (indeed very appropriate) in King's case. The police, the government, White citizens, etc., did have a commitment to combat racial injustice and provide equal treatment under the law for all citizens, a commitment that King (correctly) believed that they had, but did not rely on them to meet. On Hawley's account, the appropriateness of distrust is not just a function of, for example, King having good reasons for his confident beliefs about the system and what people will do (as Krishnamurthy discusses on 394), but is moreover a function of facts about people's commitments, which can help us screen off cases of seeming distrust in which such commitments are absent. For example, this would allow one to explain why it would not be appropriate for White citizens to distrust fellow White citizens who fail to demonstrate race-based partiality on the reasonable assumption that there is in fact no commitment to do so. This may allow us to sort out the appropriateness of different cases of what Krishnamurthy calls "social distrust" (396) based on factors that go beyond the mere beliefs of the distrusters.

Though neither affective attitudes nor the participant stance are explicitly built into Hawley's account, she does note that "attitudes such as resentment are to the fore in situations of distrust." 8 We could make this observation explicit in the account by adding that distrust involves appropriate resentment toward those on whom we do not rely to meet their commitments. Krishnamurthy mentions that distrust sits among other "negative attitudes," such as anger, that have historically been ignored as sources of political value, yet her account of distrust seems to lack any explicit affective element. It seems plausible that an account of distrust that more explicitly integrated affective elements, such as anger and resentment, into the account itself would provide an even more robust vehicle for that political value. The motivational force of emotions could help further explain how distrust could function as a catalyst for political action (on top of confident beliefs about injustice). Given Krishnamurthy's broader interest in vindicating the political value of negative attitudes, coupled with the role of affective elements in other theories of (dis)trust, it seems that an explicit affective element would better secure distrust's political value.

Putting together Hawley's account of distrust with an affective element yields a view that registers more successfully along the political metrics suggested by Krishnamurthy: Because it is voluntary and affective, it is better

system is not necessarily incompatible with relying on it (for social services, etc.). Moreover, because of the difference between belief and reliance with respect to their voluntariness, I think it is helpful to distinguish these elements and make them explicit.

${ }^{8}$ Hawley 2014: 7. 
poised to motivate political action, and it includes conditions for appropriateness that allow us to differentiate politically worthy forms of distrust from those that, though motivationally efficacious, are corrupt (such as racist forms of social distrust). Moreover, though, I believe this richer account of distrust can help us see how distrust is not merely instrumentally valuable for democratic societies, but might rather constitute a core democratic value. If distrust has merely instrumental democratic value, especially of the causal variety that Krishnamurthy describes, then there is a sense in which it is no different from the horrible police brutality that also played an instrumental role in fomenting political action during the Black Civil Rights Movement (to continue with Krishnamurthy's example). But, if that is the case, then it is perhaps unsurprising that distrust has received little attention from democratic theorists: All kinds of things causally influence political action and thus might be said to have instrumental democratic value.

In contrast, using Hawley's account, we can see that distrust may have more than just instrumental democratic value. To not rely on others to meet their commitments (in particular, when you have good reason to believe that they will not meet them) is part and parcel of the participatory nature of democratic society. Krishnamurthy notes that distrust can be an extension of Madisonian "checks and balances" meant to guard against tyranny. This is an outcome-oriented account of distrust's democratic value, which is part of the reason it is contingent: It either helps achieve this end or it does not. However, I would suggest that the process of cultivating a healthy distrust, particularly of elected representatives, is constitutive of a well-functioning democracy, independently of whether or not it happens, in a given instance, to guard against tyranny. Indeed, one might think this is the primary value of the freedom of the press championed by Madison. Moreover, this need not be incompatible with the kind of civic solidarity (or, in Krishnamurthy's terms, horizontal trust) that many democratic theorists believe is essential to a wellfunctioning democracy.

In conclusion, then, I believe Krishnamurthy is correct to emphasize the democratic value of distrust. However, I am skeptical that the particular account of distrust that Krishnamurthy develops from King is adequate to capturing that value, nor the centrality of its place in a democratic society. ${ }^{9}$

Erich Hatala Matthes

Wellesley College

Department of Philosophy

ematthes@wellesley.edu

9 An earlier version of these comments was presented at the 2015 Bellingham Summer Philosophy Conference. Thanks to Meena Krishnamurthy for her thought-provoking paper, to Rachel Anne McKinney for discussion and to Kate Manne for the invitation to comment. 


\section{References}

Hawley, K. (2014) “Trust, Distrust and Commitment," Nous 48(1): 1-20.

Holton, R. R. (2006) "Deciding to Trust, Coming to Believe," Australasian Journal of Philosophy 72(1): 63-76.

Jones, K. (2004) "Trust and Terror," in P. DesAutels and M. Urban Walker, eds., Moral Psychology, Lanham, Mass.: Rowman and Littlefield. (1996) "Trust as an Affective Attitude," Ethics 107(1): 4-25.

Krishnamurthy, M. (2015) "(White) Tyrrany and the Democratic Value of Distrust," The Monist 98(4): 391-406. 